\title{
EVALUASI KINERJA SUMBER DAYA MANUSIA \\ PENGUJI KENDARAAN BERMOTOR \\ DI ERA OTONOMI DAERAH
}

\section{Ujang Cahyono}

Dosen STTD

Jl. Raya Setu No. 89, Cibuntu, Cibitung, Bekasi 17520

Telp./Fax : (021) 8254640
Jopie Jehosua

Dosen STTD

J1. Raya Setu No. 89, Cibuntu, Cibitung, Bekasi 17520

Telp./Fax : (021) 8254640

\section{Dani Hardianto}

Dosen STTD

J1. Raya Setu No. 89, Cibuntu, Cibitung, Bekasi 17520

Telp./Fax : (021) 8254640
Ricko Yudhanta

Dosen STTD

J1. Raya Setu No. 89, Cibuntu, Cibitung, Bekasi 17520

Telp./Fax : (021) 8254640
Herdi Santoso

Instruktur STTD

J1. Raya Setu No. 89, Cibuntu,

Cibitung, Bekasi 17520

Telp./Fax : (021) 8254640

\begin{abstract}
The purpose of this study is to determine the performance testing of motor vehicles (PKB) in various regions before and decentralization. The performance is how the level of motor vehicles testing service to the community in various regions associated with the availability and readiness of test equipment, human resources and procedures. The next goal is to determine the condition of the test equipment used, the amount of human resources involved in testing, test infrastructure conditions available and the procedures to be used. The study used two of data is secondary data and primary data, secondary data required for analysis while the primary data used for observation, surveys and interviews. The results showed that there are tools or test equipment damage, human resources are limited and not yet competent, working procedures are not properly socialized and infrastructure that are not standard. This is clearly an effect on the quality of service and the quality of the test results. The insistence of the fulfillment of the regional income also affects the pattern of test services in the area.
\end{abstract}

Keywords: Performance, Testing Motor Vehicles, Human Resource Management 


\begin{abstract}
ABSTRAKSI
Tujuan penelitian ini adalah untuk mengetahui kinerja pengujian kendaraan bermotor (PKB) di berbagai daerah pada saat sebelum dan di era otonomi daerah. Kinerja tersebut adalah bagaimana tingkat pelayanan pengujian kendaraan bermotor kepada masyarakat di berbagai daerah dikaitkan dengan ketersediaan dan kesiapan alat uji, SDM, dan prosedur yang berlaku. Tujuan berikutnya adalah untuk mengetahui kondisi peralatan uji yang digunakan, jumlah SDM yang terlibat dalam pengujian, kondisi prasarana uji yang tersedia serta prosedur yang digunakan. Penelitian menggunakan dua data yaitu data sekunder dan data primer, data sekunder dibutuhkan sebagai bahan analisis sedangkan data primer digunakan untuk observasi, survei dan wawancara. Hasil penelitian menunjukkan bahwa terdapat peralatan atau alat uji yang mengalami kerusakan, sumber daya manusia yang terbatas dan belum kompeten, prosedur kerja yang tidak tersosialisasi dengan baik dan prasarana yang tidak standar. Hal tersebut jelas berpengaruh pada mutu pelayanan dan kualitas hasil ujinya. Adanya desakan pemenuhan pendapatan daerah juga berpengaruh pada pola pelayanan uji di daerah.
\end{abstract}

Kata kunci : Kinerja, Pengujian Kendaraan Bermotor, Manajemen Sumber Daya Manusia

\title{
PENDAHULUAN
}

\section{Latar Belakang}

Seiring pelaksanaan Otonomi Daerah dengan penyelenggaraan pengujian berkala kendaraan bermotor adalah kewenangan pemerintah daerah Kabupaten/Kota, ditemui beberapa kendala antara lain terdapat keterbatasan tenaga penguji dengan kualifikasi teknis tertentu, banyak Kabupaten/Kota dalam melaksanakan pengujian dengan peralatan yang tidak memenuhi persyaratan teknis yang telah ditetapkan atau tidak memiliki peralatan dan tenaga penguji tetapi melakukan pengujian, pelaksanaan pengujian dengan sistem prosedur yang tidak memenuhi persyaratan, maupun biaya uji yang tidak standar dan bervariasi antar Kabupaten/Kota.

Direktur Jenderal Perhubungan Darat selaku pembina dan pengawas teknis terhadap pelaksanaan pengujian berkala kendaraan bermotor, wajib dan perlu melaksanakan pembinaan dan pengawasan teknis tersebut di antaranya berupa evaluasi terhadap pemenuhan persyaratan fasilitas/peralatan pengujian, tenaga penguji dan prosedur pengujian di masing-masing unit pelaksana pengujian berkala kendaraan bermotor, terkait juga dengan kinerja Pengujian Kendaraan Bermotor setelah Otonomi Daerah yang telah 
dilakukan oleh Pemerintah Daerah Kabupaten / Kota. Evaluasi tersebut diharapkan dapat menggambarkan kinerja setiap unit pelaksana pengujian berkala kendaraan bermotor di seluruh Indonesia. Pelaksanaan pengujian berkala kendaraan bermotor yang mencakup kegiatan-kegiatan yang berkaitan dengan fasilitas dan peralatan pengujian, sistem dan prosedur pengujian, serta sumber daya manusia yang memiliki kualifikasi teknis tertentu dimaksudkan untuk memenuhi amanat konstitusi.

Berdasarkan uraian di atas, maka dalam penulisan penelitian ini, peneliti tertarik untuk mengambil judul: "Evaluasi Kinerja SDM Penguji Kendaraan Bermotor di Era Otonomi Daerah".

\section{METODOLOGI PENELITIAN}

\section{Metode Pengumpulan Data}

Dalam melaksanakan penelitian, untuk memperoleh hasil yang baik maka diperlukan sejumlah data pendukung agar dapat dilakukan analisa data. Data yang dibutuhkan untuk penelitian ini berdasarkan dari data sekunder dan data primer.

Data sekunder yang dibutuhkan untuk mendukung sebagai bahan analisis dalam penelitian ini antara lain seperti Kualifikasi tenaga penguji dalam pengujian kendaraan bermotor, Metoda pelaksanaan pengujian kendaraan bermotor, Persyaratan teknis peralatan yang digunakan dalam pengujian kendaraan bermotor, Sistem prosedur dalam pelaksanaan pengujian kendaraan bermotor, Biaya uji dalam pelaksanaan pengujian kendaraan bermotor, Rencana Kerja UPT Pengujian Kendaraan Bermotor, Laporan Bulanan / Semester UPT Pengujian Kendaraan Bermotor.

Data primer yang dibutuhkan pada penelitian ini antara lain: observasi, survei questioner, wawancara.

\section{Metode Penelitian}

Kuesioner sebagai instrumen penelitian dibuat berdasarkan kerangka teoretik yang dikukuhkan dalam bentuk definisi konseptual dan definisi operasional yang kemudian disajikan dalam bentuk kisi-kisi instrumen penelitian. Dari kisi-kisi tersebut selanjutnya dijabarkan dalam butir-butir pernyataan dan kemudian diuji coba (dengan pengujian validitas dan reliabilitas) sebelum digunakan untuk penelitian.

Pada dasarnya data yang dikumpulkan semaksimal mungkin diusahakan dari sumber sekunder, survey primer dilakukan jika data sekunder tidak tersedia atau untuk mengkonfirmasi (validasi) data sekunder dengan kondisi nyata di lapangan. Survei 
sekunder dilakukan untuk memperoleh data kinerja pengujian kendaraan bermotor pasca otonomi daerah secara langsung dan resmi dari lingkungan Kementerian Perhubungan, Ditjen Perhubungan Darat, Lalu Lintas dan Angkutan Jalan yang dapat mewakili kondisi pengujian kendaraan bermotor di Indonesia pasca otonomi daerah antara lain; kualifikasi tenaga penguji, pelaksanaan pengujian dengan peralatan yang tidak memenuhi persyaratan teknis yang telah ditetapkan, pelaksanaan pengujian dengan sistem prosedur yang tidak memenuhi persyaratan, maupun biaya uji yang tidak standar dan bervariasi antar Kabupaten/Kota.

\section{Sampel Penelitian}

Dalam penelitian ini, populasinya adalah pegawai penguji kendaraan bermotor di Dinas Perhubungan DKI Jakarta. Sebagai populasi terjangkau atau populasi target untuk kerangka sampel adalah penguji kendaraan bermotor di Unit Pengujian Kendaraan Bermotor (UPTD) Dinas Perhubungan Provinsi DKI Jakarta yang berjumlah 120 orang tersebar pada empat wilayah: 1) Pelayanan PKB Ujung menteng, 2) Pelayanan PKB Pulo Gadung, 3) Pelayanan PKB Kedaung Angke, 4) Pelayanan PKB Cilincing, pegawai tersebut sebagai populasi terjangkau.

\section{ANALISIS DAN PEMBAHASAN}

Beberapa kondisi jumlah penguji berdasarkan pembagian wilayah kajian adalah sebagai berikut:

\section{Jakarta Timur}

Kecukupan jumlah tenaga penguji dari 2 lokasi kajian menunjukan bahwa memiliki jumlah penguji yang sangat cukup (mencapai tingkat kecukupan melebihi 95\%), yaitu PKB Ujung Menteng dan PKB Pulo Gadung, dari kebutuhan jumlah minimum untuk jumlah penguji dalam satu line pengujian.

2. Jakarta Barat

Kecukupan jumlah tenaga penguji dari 1 lokasi kajian menunjukan bahwa memiliki tingkat kecukupan jumlah penguji dibawah 90\% dari kebutuhan jumlah minimum untuk jumlah penguji dalam satu line pengujian.

3. Jakarta Utara

Kecukupan jumlah tenaga penguji dari 1 lokasi kajian menunjukan bahwa memiliki tingkat kecukupan jumlah penguji dibawah $80 \%$ dari kebutuhan jumlah minimum untuk jumlah penguji dalam satu line pengujian. 
Kondisi Khusus yang ditemukan pada saat melakukan survey lapangan mengenai kondisi penguji atau sumber daya manusia di setiap UPT PKB Kabupaten/Kota yang terlibat dalam pelaksanaan mekanisme dan standar Pengujian dapat dirangkum berdasarkan beberapa kondisi sebagai berikut:

1. Adanya perekrutan atau pemberdayaan tenaga pelaksana Pengujian Kendaraan Bermotor kurang kompeten yang diikutsertakan dalam pelaksanaan mekanisme dan prosedur pengujian sehingga efeknya dapat mengurangi kualitas kinerja pelayanan serta output dari Pengujian Kendaraan Bermotor itu sendiri.

2. Di lapangan masih terdapat tenaga penguji fungsional yang masih merangkap tugas, contoh dia bertindak sebagai approval/checker, namun dia juga terlibat dalam proses teknis pengujian.

Hal ini dikarenakan faktor kekurangannya tenaga penguji yang tersedia, walaupun memang secara prosedur menyalahi namun melihat dari pentingnya ketersediaan tenaga yang kompeten terutama Pengujian Kendaraan bermotor ini menyangkut akan keselamatan pengendara pribadi dan pengendara yang lainnya maka hal tersebut menjadi hal yang layak untuk dilakukan walaupun masih harus diadakan pembenahan khusus.

3. Masih adanya Pungutan Liar, sehingga biaya pengujian yang dikeluarkan oleh pemilik kendaraan yang melakukan pengujian tidak sesuai (membengkak) dengan tarif dasar yang seharusnya diberlakukan. Hal tersebut terjadi dikarenakan orientasi yang ditumbuhkan dalam UPT PKB tersebut adalah untuk mengejar PAD, serta kebutuhan untuk mencari penghasilan bukan sebagai sarana pelayanan dan penanggulangan keselamatan para pengguna kendaraan.

Berdasarkan kondisi yang ditemukan di lapangan pada saat melakukan survey terdapat beberapa UPT PKB Kabupaten/Kota yang masih lekat dengan keberadaan calo dalam proses Pengujian Kendaraan Bermotor, malah bagi beberapa UPT yang sempat dilakukan survey keberadaan calo mampu mempermudah proses pengujian bagi para pemilik kendaraan yang hendak melaksanakan pengujian.

Dibiarkan menjamurnya calo, serta adanya atau dibukanya kerjasama antara petugas pengujian dengan calo, sehingga tidak menutup kemungkinan mempengaruhi standar operasional prosedur yang seharusnya diberlakukan dan diterapkan dalam UPT PKB tersebut.

4. Adanya petugas-petugas yang tidak bertanggung jawab dengan tidak menjalankan sistem dan prosedur sesuai dengan seharusnya, sehingga membuka kesempatankesempatan akan timbulnya penyelewengan-penyelewengan yang lain. 
5. Kurangnya sosialisasi mengenai alur dan prosedur pengujian kendaraan baik itu berupa papan pengumuman, baner, spanduk, dll, yang menjelaskan mengenai proses dan alur pengujian kendaraan bermotor.

6. Kurangnya pengetahuan dari para petugas pengujian sehingga tidak mampu mensosialisasikan kepada para pemilik kendaraan wajib uji.

7. Kurangnya kesadaran para pemilik kendaraan uji akan pentingnya keselamatan dan proses pengujian kendaraan bermotor, sehingga memillih cara-cara instan dan enggan untuk melakukan pengujian itu sendiri, serta enggan mencari tahu alur dan proses pengujian itu seperti apa, sehingga lebih memilih untuk menggunakan tenaga calo.

Faktor Penyebab:

1. Kurangnya sosialisasi mengenai alur dan prosedur pengujian kendaraan baik itu berupa papan pengumuman, baner, spanduk, dll, yang menjelaskan mengenai proses dan alur pengujian kendaraan bermotor.

2. Dibiarkan menjamurnya calo, serta adanya atau dibukanya kerjasama antara petugas pengujian dengan calo, sehingga tidak menutup kemungkinan mempengaruhi standar operasional prosedur yang seharusnya diberlakukan dan diterapkan dalam UPT PKB tersebut.

3. Kurangnya pengetahuan dari para petugas pengujian mengenai persyaratan pengujian kendaraan bermotor itu sendiri, sehingga tidak mampu mensosialisasikan kepada para pemilik kendaraan wajib uji.

4. Kurangnya kesadaran para pemilik kendaraan uji akan pentingnya keselamatan dan proses pengujian kendaraan bermotor, sehingga memillih cara-cara instan dan enggan untuk melakukan pengujian itu sendiri, serta enggan mencari tahu alur dan proses pengujian itu sendiri, sehingga lebih memilih cenderung untuk menggunakan jasa calo.

Berdasarkan hasil analisis yang dilakukan terhadap komponen fisik dari pelaksanaan pengujian kendaraan bermotor, yaitu alat uji dan personil uji, berikut disajikan diagram ketersediaan untuk setiap wilayah kajian pada gambar di bawah ini. 


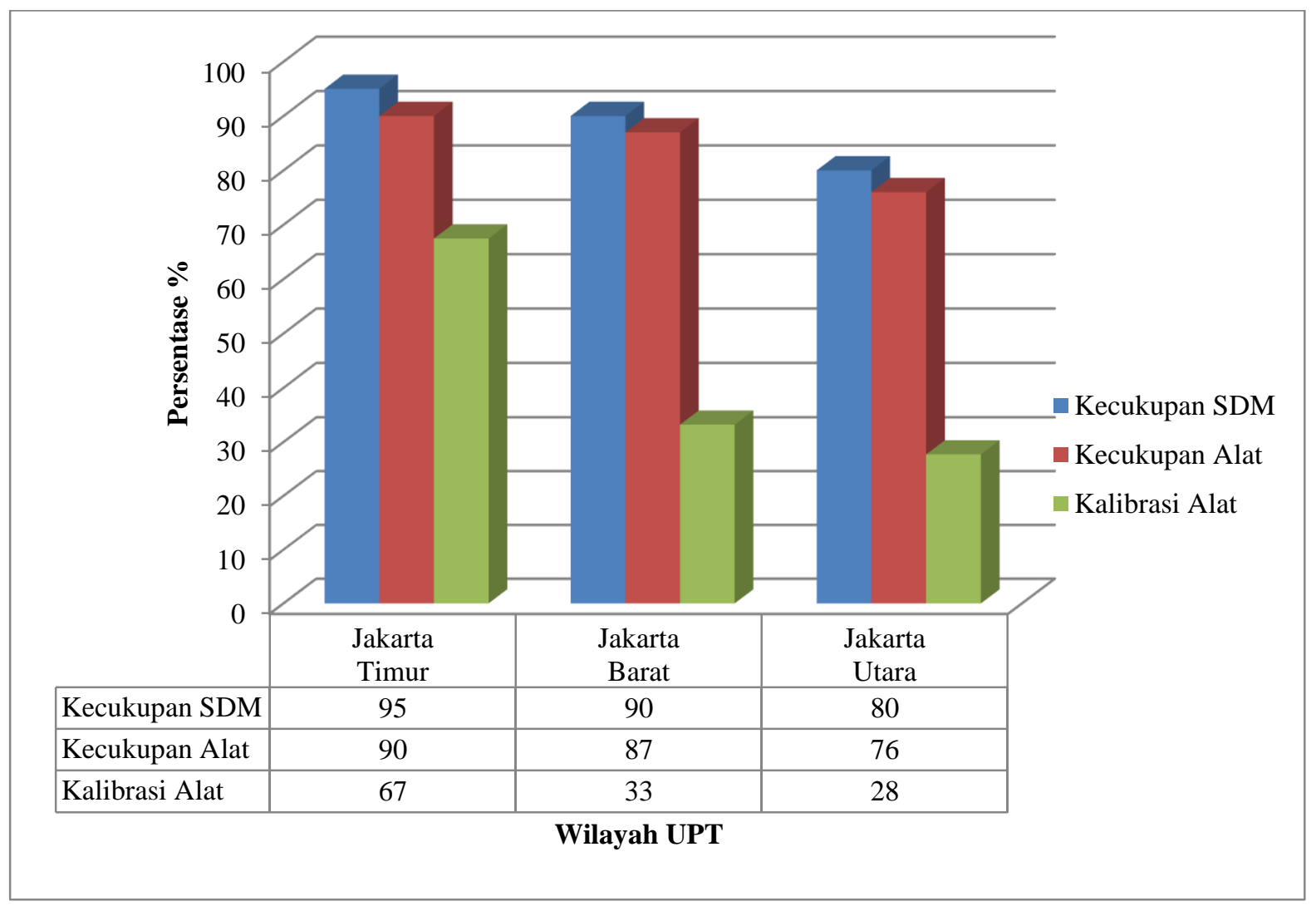

Gambar 1. Resume Kondisi Fisik Lokasi Pengujian Kendaraan Bermotor

Dari diagram di atas dapat dilihat bahwa wilayah Jakarta Timur memiliki kecukupan tenaga penguji dan alat yang paling baik dibandingkan dengan wilayah kajian lainnya, sehingga dalam perencanaan pengembangan diperlukan adanya perangkingan terhadap wilayah prioritas yang perlu untuk dikembangkan.

\section{DAFTAR PUSTAKA}

Anwar Prabu Mangkunegara. 2005. Evaluasi Kinerja. Bandung : Refika Aditama.

Simanjuntak, Payaman J. 2005. Manajemen dan Evaluasi Kerja. Lembaga Penerbit FEUI, Jakarta.

Ika UT. 2009. "Makalah Evaluasi Kinerja 1" Ikatan Alumni Universitas Terbuka Jakarta. http://ika-utjakarta.blogspot.com/2009/11/makalah-evaluasi-kinerja-1.html

Dwiyanto, Agus, 1995. Penilaian Kinerja Organisasi Pelayanan Publik, makalah disampaikan pada seminar Kinerja Organisasi Publik, FISIPOL UGM, Yogyakarta

Gibson, dkk, 1993. Organisasi dan Manajemen, Perilaku, Struktur dan Proses, Erlangga, Jakarta 
Indrawijaya, Adam I. 2000. Perubahan Perilaku Organisasi, Penerbit Sinar Baru ALGASINDO, Bandung

Keban, Yeremias T. 1995. Indikator Kinerja Pemerintah: Pendekatan Manajemen dan Kebijakan, Makalah disajikan pada seminar sehari Kinerja Organisasi Politik, FISIPOL UGM, Yogyakarta

Kusnadi, H. HMA, dkk. 2002. Pengantar Manajemen (Konsepsual dan Perilaku), Unibraw, Malang.

Bryson, John M, 1999. Perencanaan Strategis bagi Organisasi Sosial, Pustaka Pelajar, Yogyakarta.

Dressler, Gerry, 1993. Human Behavior, Improving Performance at Work, Reston Publishing Co, Inc, Virginia. 